\title{
¿SON POSIBLES LAS POLÍTICAS PÚBLICAS FRENTE A LAS TRANSNACIONALES?
}

\author{
Magdalena León \\ Integrante de la Fundación de Estudios, Acción y Participación Social - FEDAEPS
}

DOI: 10.1387/lan-harremanak.16096

\section{ABSTRACT}

La posibilidad de articular politicas públicas que delimiten y disputen el poder de las empresas transnacionales, se ha presentado en el marco de experiencias que buscan salir del neoliberalismo y transitar hacia un nuevo sistema económico, lo cual ha supuesto plantearse la refundación constitucional de los Estados, redefiniendo objetivos estratégicos, instituciones, normas y demás, como es el caso de Ecuador.

El artículo hace una breve revisión de iniciativas de politicas públicas que hacen frente al poder de las transnacionales, de manera directa o indirecta, desde agendas especificas de recuperación de soberanías, control del poder de mercado y compras públicas. Desplegando las capacidades de regulación, control y negociación del Estado, y conjugando soberanías nacionales y regionales, se procura delimitar el control transnacional de la producción y el comercio, de la capacidad de demanda local, entre otros, lo que pasa por reestructuraciones de los propios mercados nacionales y de sus lógicas.

Palabras clave: empresas transnacionales, politicas públicas, Estados, transición, soberanía.

The possibility of making public policy to restrict and dispute the power of the transnationals arises within the framework of experiences seeking to escape from neoliberalism and make a transition towards a new economic system, which has meant raising the possibility of constitutional refounding of states, by redefining strategic goals, institutions, rules and more, as in the case of Ecuador. 
The article briefly reviews public policy initiatives to confront the power of the transnationals, directly or indirectly, on the basis of specific agendas for recovering sovereignties, controlling the power of the market and public procurement. By rolling out powers of regulation, control and negotiation by the state, and combining national and regional sovereignties, the aim is to set boundaries for transnational control of production and trade and the capacity of local demand, among other things, which involve reshaping national markets themselves, and their logic.

Keywords: transnational corporations, public policy, states, transition, sovereignty.

Enpresa transnazionalen boterea mugatu eta aurka egiteko politika publikoak egiteko aukera, neoliberalismotik atera eta sistema ekonomiko berri baterantz joateko esperientzien barruan aurkeztu izan da. Honek ekarri du Estatuen konstituzioen birsortzea eta helburu estrategikoak, erakundeak, arauak eta abar zehaztea, Ecuadorren gertatu den bezala.

Artikulu honek, enpresa transnazionalei, zuzenean edo zeharka, aurre egiteko politika publikoen ekimenak laburki berrikusten ditu: burujabetzak berreskuratzeko agenda espezifikoak, merkatuaren boterearen kontrola eta erosketa publikoak. Estatuaren arautze, kontrol eta negoziazio gaitasunetik abiatu eta herrietako eta erregioetako burujabetzak elkartuz, helburua da ekoizpen eta merkataritzaren kontrol transnazionala eta tokiko demanda gaitasunarena zehaztea, besteak beste. Honetarako herrietako merkatuak eta bere logikak berregituratu behar dira.

Hitz gakoak: enpresa transnazionalak, politika publikoak, Estatuak, trantsizio, burujabetza. 


\section{Introducción}

Las preocupaciones por la presencia y por los impactos negativos múltiples de las transnacionales en las economías y sociedades de los países del Sur se han traducido, de manera preponderante, en iniciativas de denuncia y propuesta desde ámbitos de la sociedad organizada, casi siempre a escala internacional, con agendas e intervenciones que buscan así mismo impactos en esa arena $^{1}$.

Dadas las relaciones de poder asimétricas entre las empresas transnacionales y los Estados, consolidadas por y para el neoliberalismo, ha sido muy escaso el despliegue de políticas públicas que busquen modificar el carácter o las repercusiones perjudiciales de la acción transnacional en las economías nacionales. Las actuaciones públicas se han dado más bien como reacción defensiva ante las demandas corporativas que se multiplican al amparo del esquema inversionista-Estado, que aplica de facto una protección de inversiones al margen de las leyes nacionales, con procedimientos internacionales arbitrarios conducidos por actores privados y bajo sus dictámenes².

La posibilidad de articular políticas públicas que delimiten y disputen el poder de las transnacionales, se ha presentado en el marco de experiencias que buscan salir del neoliberalismo y transitar hacia un nuevo sistema económico, lo cual ha supuesto plantearse la refundación constitucional de los Estados, redefiniendo objetivos estratégicos, instituciones, normas y demás, como es el caso de Ecuador, que a partir de 2007 busca una transformación bajo el proyecto denominado Revolución Ciudadana.

En estas líneas se muestran algunas de las iniciativas de políticas públicas actualmente en vigencia que, de manera directa o indirecta, hacen frente al poder

${ }^{1}$ Para sólo citar un ejemplo, se ha planteado la necesidad de avanzar en un nuevo Derecho Corporativo Global, dado que "...no existen contrapesos suficientes ni mecanismos efectivos para controlar sus impactos sociales, laborales, culturales y ambientales» (Hernández et al., 2014: 3).

2 Tal el caso de la demanda contra el Estado ecuatoriano por parte de la Occidental Petroleum Corporation (Oxy), uno de las decenas de procesos en curso en la región. 
de las transnacionales, desde agendas específicas de recuperación de soberanías, control del poder de mercado y compras públicas ${ }^{3}$.

\section{Soberanías}

La Constitución ecuatoriana adoptada en 2008 tiene como uno de sus pilares el enunciado de soberanías en plural. La refundación del Estado que se propone a través de este texto organizador de la vida pública del país, supone no sólo rescatar y dar nueva vigencia a la soberanía nacional, sino reflejar los ámbitos y procesos que, en el devenir histórico reciente, han emergido en el marco de las tensiones y conflictos con el poder transnacional. Son, en buena medida, formulaciones generadas en dinámicas en que confluyen la contestación social y la elaboración de alternativas, que han producido también una conceptualización innovadora.

Se trata de la soberanía energética, la soberanía económica y financiera, la soberanía tecnológica y de los conocimientos, la soberanía alimentaria ${ }^{4}$, entre otras. Su acepción general tiene que ver con la toma de decisiones autónoma, sin imposiciones, y el control de recursos en función de objetivos nacionales vinculados al bien común y al Buen Vivir.

Estas soberanías suponen construir las posibilidades ciudadanas para su cabal ejercicio, con un sentido de derechos y responsabilidades ${ }^{5}$ :

En el proceso político que vive Ecuador, este concepto trasciende la definición tradicional para transmutar en algo más abarcador, más integral. Básicamente, la soberanía se comprende como el deber y el derecho de un pueblo, de una sociedad, a decidir sobre los temas que son de su interés directo, sin tutelajes ni imposiciones. Sin embargo, para que esta noción se sostenga, resulta perentorio contar con un pueblo deliberante, una ciudadanía activa e informada que tome decisiones de acuerdo al bien común, que abrace al interés público (Espinosa, 2013, p. 56).

Amparado en esta recuperación / estreno de soberanías, el país ha encarado conflictos en curso o asuntos de importancia estratégica ${ }^{6}$ vinculados al poder

3 Avances de estas experiencias fueron presentados en el Taller Internacional Politicas públicas frente a las transnacionales. Experiencias de Ecuador y Bolivia, coorganizado por la Superintendencia de Control del Poder de Mercado, OMAL, FEDAEPS, CIESPAL y Campaña La Mano Sucia de Chevron, Quito, julio 2015.

${ }^{4}$ Quizá la que presenta una trayectoria más nítida, una formulación más acabada y un soporte social de alcances globales, y que con esas cualidades encontró un espacio incontestable en el texto constitucional.

5 Según Hinkelammert, bajo el actual dominio del mercado la soberanía popular ha sido convertida en soberanía del capital.

${ }^{6}$ La definición constitucional de sectores estratégicos resulta indisociable de la correspondiente a soberanías, ambas se vinculan y complementan en función del objetivo mayor de construcción del 
transnacional. Un conjunto de políticas e intervenciones públicas se ubican en este campo, entre ellas:

a) La renegociación de contratos con las empresas petroleras, que permitió rescatar ingresos públicos encaminados principalmente a la inversión social.

b) La recuperación de la Base de Manta, base militar manejada durante la década previa por Estados Unidos con fines de «control del narcotráfico» en la región.

c) La realización de una pionera auditoría de la deuda, basada en conceptos nuevos como deuda ilegítima, deudas ecológica, histórica, de género, que permitió una renegociación ventajosa del tramo comercial de la deuda externa y redireccionar esos recursos hacia iniciativas de redistribución.

d) La denuncia de los Tratados Bilaterales de Inversiones - TBI_, proceso que lleva adelante el poder legislativo, cuyos informes se derivan al Presidente de la Republica, quien emite decretos para el cese de cada uno de los contratos y da a conocer esta decisión al país contraparte. Junto con ello, la auditoría de los TBI, desarrollada en base a los criterios y experiencias acumuladas con la auditoría de la deuda.

e) Los avances en mecanismos de integración regional —que aluden también a la noción de soberanía regional - orientados a una nueva arquitectura financiera, comercio compensado, compras públicas regionales, entre otros.

A la hora de encarar el poder transnacional desplegado en territorios concretos, en condiciones concretas, ha saltado la evidencia de que se trata de un problema común que cada pais vive de manera propia ${ }^{7}$, lo cual supone el desarrollo de estrategias situadas pero convergentes con otras similares, y articuladas en espacios regionales e internacionales.

\section{Poder del mercado}

Uno de los debates más circunscritos al perfeccionamiento del mercado tiene que ver con la creación de condiciones para la competencia, a fin de evitar el control monopólico del mercado. Este supuesto del sistema capitalista resulta

Buen Vivir, al igual que en términos más prácticos y concretos en los niveles administrativo, legal y otros.

7 En palabras de Juan Carlos Alurralde, Vicecanciller del Estado Plurinacional de Bolivia, quien intervino en el Taller Internacional Políticas públicas frente a las transnacionales. Experiencias de Ecuador y Bolivia, Quito, julio 2015. 
falaz si, como señala Harvey «... el poder de los monopolios es básico y no una aberración en el funcionamiento del capital... existe una unidad contradictoria con la competencia», y si el poder de clase del capital se puede definir por su «monopolio colectivo sobre los medios de producción (o en una versión más reciente sobre los medios de financiación)» (Harvey, 2015: 138).

Si en cualquier economía resulta legítimo buscar un espacio para la disputa desde la perspectiva de actores económicos que concurren al mercado en condiciones asimétricas, sea en términos de información como del conjunto de condiciones inherentes al proceso de producción y comercialización, más aún si, como se ha verificado en la economía ecuatoriana contemporánea, operan fuertes tendencias de concentración del poder de mercado, entre cuyas consecuencias está la eliminación de las pequeñas y medianas unidades productivas y comerciales, algunas de ellas basadas en lógicas no empresariales, sino de economía popular o de economía social y solidaria.

En este escenario concreto, el fomento de la competencia adquiere un sentido distinto de aquel vinculado al principio de libertad de mercado, pues junto con medidas de regulación se busca preservar y ampliar el acceso al mercado de una diversidad de actores económicos que, de otro modo, estarían condenados a la exclusión en el marco de relaciones de poder completamente asimétricas.

Una nueva institución que hace parte de las funciones de control del Estado ecuatoriano, la Superintendencia de Control del Poder de Mercado - SCPM — ${ }^{8}$, ha desplegado varias políticas en el ámbito de la competencia, no desde la óptica de proteger el libre mercado, sino de control de la concentración y de generación de condiciones de equidad para los diversos operadores económicos, desde el lado de la oferta, y cambiar pautas de consumo y participación en el lado de la demanda; el instrumento privilegiado ha sido el cambio en la estructura de incentivos para productores y consumidores?. Todo esto hace parte de una disputa al espacio alcanzado por las transnacionales, en un escenario previo de ausencia de control.

a) El control de la concentración hace parte de las acciones para prevenir los abusos de poder del mercado. La SCPM tiene la atribución legal de autorizar, negar o condicionar las operaciones entre empresas u operadores económicos en general, incluyendo las transnacionales que intervienen en tales transacciones, para evitar la concentración. Asimismo, tiene la capacidad de sancionar cuando se haya producido un abuso de

\footnotetext{
${ }^{8}$ En funcionamiento desde 2013 en aplicación de la Ley Orgánica de Control del Poder de Mercado, promulgada en 2011.

9 Información presentada por Rubén León, de la SCPM, en el Taller Internacional Políticas públicas frente a las transnacionales. Experiencias de Ecuador y Bolivia, Quito, julio 2015.
} 
poder ${ }^{10}$. En el despliegue de esta política se ha constatado cuán opaca se torna la identificación o distinción de operadores aparentes y reales, en un ámbito nacional inexorablemente vinculado a un escenario mundial en que el $40 \%$ del mercado está controlado por 150 operadores transnacionales, tres cuartas partes de los cuales son financieros. Sus ramificaciones atraviesan el mundo, en constantes dinámicas de traspasos accionarios, cambios de razón social, de sede, etc., de manera que seguir el rastro de quién está detrás de determinados operadores económicos, en función del control de concentración, resulta una tarea compleja. Se han identificado distintas formas de concentración que van más allá de la propiedad, como son la confluencia de operadores transnacionales en distintos procesos de operación o de dotación de insumos para un mismo servicio en el territorio nacional, frente a lo cual se ha exigido o recomendado la subcontratación con proveedores nacionales. Ha sido evidente también la importancia y necesidad de impulsar una política de control y regulación a nivel regional, pues, entre otras consideraciones, las transnacionales definen sus planes y estrategias a esa escala (por ejemplo, América Latina y El Caribe se consideran un mercado). Por ello se ha propiciado un grupo de trabajo de política de competencia a nivel regional, en la perspectiva de una acción concatenada, para ejercer capacidades regulatorias que se complementen con aquellas de compra y contratación (especialmente pública).

b) En el ámbito del cambio de incentivos a la producción y al consumo se han generado varias políticas e instrumentos. Frente a la producción, se trata de generar condiciones equitativas de participación en los mercados, para lo cual se ubican las problemáticas de sectores estratégicos (por ejemplo alimentación y salud), y se diseñan intervenciones para atenderlas. En la relación con las transnacionales, se trata de generar producción nacional que pueda competir y disputar espacios en el mercado, pero contando con herramientas que compensen las condiciones de desventaja competitiva intrínseca. Así, en el de los supermercados, se identificó una concentración de compras y otras formas de trato desigual a pequeños y medianos proveedores, frente a lo cual se generaron manuales de buenas prácticas comerciales y códigos de ética, mediante los que se incentiva a modificar la estructura de compra (con compromisos para cuotas anuales ascendentes para la producción nacional, especialmente de unidades de economía popular y social y solidaria), modalidades de pago y otros. En corto plazo los resultados positivos han sido evidentes. Igual se ha procedido con el caso de salud y medicinas, donde el desafío ha sido revertir una ace-

10 Las sanciones pueden llegar al 12\% de los ingresos netos. La sanción aplicada a la empresa de telecomunicaciones Claro alcanzó US\$138.5 millones. 
lerada tendencia hacia la concentración, pues en pocos años había desaparecido un $45 \%$ de las farmacias independientes en beneficio de las grandes cadenas.

d) Desde el lado del consumo o la demanda, y haciendo uso de definiciones constitucionales respecto de la participación ciudadana y sus formas de organización, se ha impulsado la conformación de comités de usuarios, que con la motivación y capacitación recibida desde la SCPM han generado procesos de vigilancia, control, reclamo, información, intercambio de experiencias, conocimiento y toma de conciencia respecto de derechos y pautas de consumo que favorezcan la producción nacional $v$ s la transnacional; su quehacer se proyecta también hacia la incidencia política y el aporte a la construcción de políticas públicas.

\section{Compras públicas}

La contratación pública es un ámbito privilegiado para el diseño de herramientas de toma de decisiones —en tensión con las regulaciones establecidas por la OMC — para estrechar el espacio de las poderosas transnacionales y ampliarlo para actores de la economía nacional, especialmente para los más pequeños.

Las políticas impulsadas desde una nueva institución, el Servicio Nacional de Contratación Pública ${ }^{11}$, se han propuesto abrir la contratación pública a la producción ecuatoriana, redistribuir la compra de modo que se logre disminuir la compra transnacional. Se ha ponderado el potencial de las políticas regulatorias de acceso como mecanismo de fomento de la producción nacional, como vector para el desarrollo endógeno.

La contratación pública tiene magnitudes ${ }^{12}$ que representan hasta un $12 \%$ del PIB y entre el 34\% y el 40\% del Presupuesto General del Estado, con un componente importado de alrededor del 40\%. Su importancia económica se acentúa en condiciones en que constitucionalmente se reconoce el sector público como uno de los sectores de la economía y, así mismo, se amplía la capacidad regulatoria del Estado.

De los 50 principales proveedores del Estado, el 60\% son empresas transnacionales y se ubican en los rubros de tecnología, medicinas y grandes obras de

11 Amparado en la Ley Orgánica del Sistema Nacional de Contratación Pública, emitida en 2008 y reformada en 2013.

12 Datos tomados de la presentación de Juan Pablo Bermeo, Subdirector General del Servicio de Contratación Pública, en el Taller Internacional Politicas públicas frente a las transnacionales. Experiencias de Ecuador y Bolivia, Quito, julio 2015. 
infraestructura. Esta tendencia supone una sistemática salida de divisas ${ }^{13}$, dependencia tecnológica, reducción del mercado para actores nacionales, y un costo de oportunidad para el impulso a la producción nacional. Como respuesta, se han diseñado cuatro líneas de intervención:

a) Acciones de regulación afirmativa para el acceso de la producción nacional a la contratación pública. Se otorga preferencia a ofertas de empresas o productos con valor agregado nacional, que participan en una ronda exclusiva. Los umbrales establecidos para este componente nacional tienen en cuenta la realidad productiva diversa del país, y por tanto son variables dependiendo de los rubros implicados. Se busca incentivar los encadenamientos y la inclusión productiva (por ejemplo se han establecido rondas exclusivas y un catálogo inclusivo para la Economía Popular y Solidaria -EPS—).

b) Convenios marco plurianuales para incentivar la inversión nacional. Desde una perspectiva de alianzas con productores nacionales, se trata de asegurar condiciones de largo plazo para proveedores que cumplen determinados requisitos, para así ofrecer certezas que incentiven nuevas inversiones. Se contemplan también condicionalidades positivas, que tienen que ver con estándares laborales y ambientales, ubicación de inversiones en zonas deprimidas y otros.

c) Requisitos a proveedores extranjeros, cuando la escala permite negociación bajo condiciones. En el caso de bienes importados de media y alta tecnología, la condición es que se opere con un socio estratégico nacional, de modo que se produzca una transferencia o adaptación de tecnológica y se de un proceso de sustitución paulatina (universidades, centros de transferencia tecnológica, empresas nacionales). Otra condición es que al menos un parte del proceso de producción se dé bajo subcontrato con nacionales.

d) Compras públicas regionales. La agregación de escala a este nivel no sólo permite una mejor negociación de precios en torno a bienes estratégicos de producción extra regional, sino también establecer condiciones similares a las definidas a nivel nacional respecto de transferencia de tecnología y subcontratación, identificar cadenas de producción intrarregionales, disminución en el uso de divisas por medio de la aplicación de mecanismos de compensación de pagos, entre otros.

¿Son, entonces, posibles políticas públicas que hagan frente al poder de las transnacionales? Estas experiencias indican que sí, haciendo uso de las capacidades de regulación, control, negociación; conjugando soberanías nacionales y re-

13 En las condiciones de pérdida de soberanía monetaria que supone la dolarización impuesta desde 2000, el flujo de divisas se ha tornado un asunto de alta vulnerabilidad. 
gionales en procura de delimitar el control transnacional de la producción y el comercio, de la capacidad de demanda local, entre otros, lo que pasa por reestructuraciones de los propios mercados nacionales y de sus lógicas.

Son búsquedas que se relacionan con varios de los vectores de disputa al poder transnacional (Fernández, 2015: 31) y con lo que Hinkelammert considera la tarea principal ante los alcances de la estrategia de globalización dominante: «...desarrollar una sociedad capaz de regular y canalizar el mercado en un grado tal, que ya no puede pronunciar condenas de muerte» (Hinkelammert, 2014: 237).

\section{Bibliografía}

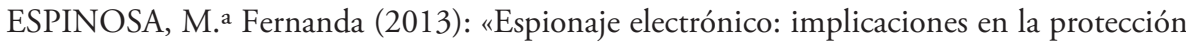
de las soberanías y los derechos humanos", Revista Linea Sur, 6, 55-62.

FERNÁNDEZ, Gonzalo (2015): "Alternativas para disputar el poder, el ser y el saber a las transnacionales», Revista Pueblos, 66, tercer trimestre, 28-31. En: http://www. revistapueblos.org/?p=19678

HARVEY, David (2015): 17 contradicciones y el fin del capitalismo, Quito, IAEN.

HERNÁNDEZ, Juan, GONZÁLEZ, Erika y RAMIRO, Pedro (2014): Tratado internacional de los pueblos para el control de las empresas transnacionales. Una apuesta desde los movimientos sociales y la solidaridad internacional, Bilbao, Hegoa.

HINKELAMMERT, Franz (2014): «La rebelión de los límites, la crisis de la deuda, el vaciamiento de la democracia y el genocidio económico-social», en CORAGGIO, José Luis y LAVILLE, Jean-Louis (coords.), Reinventar la izquierda en el siglo XXI, Quito, IAEN.

LEÓN, Magdalena (2008): «Deuda y soberanía financiera: contexto y propuestas de cambio constitucional», en WEBER, Gabriela (coord.), Deuda ilegitima. Aportes al debate, Quito, Observatorio de la Cooperación al Desarrollo en el Ecuador / GND. 